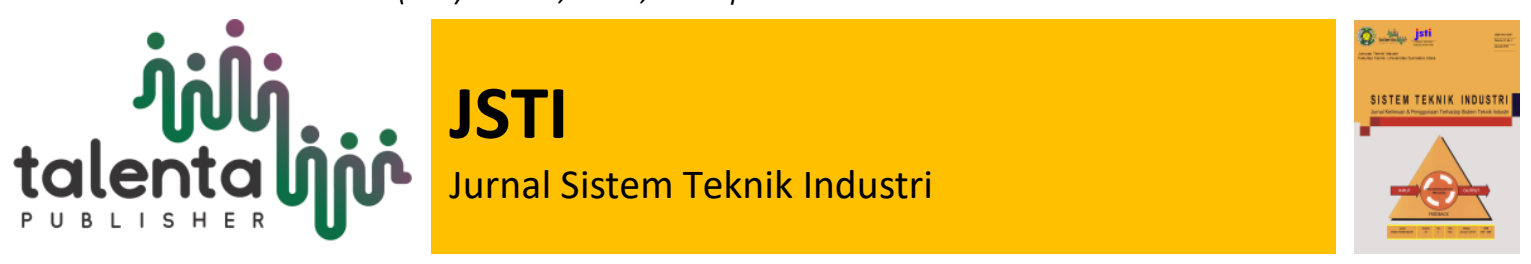

\title{
Perancangan Shelter Bus Mebidang Dengan Menggunakan Quality Function Deployment (QFD)
}

\author{
Chalis Fajri Hasibuan ${ }^{1}$, Sutrisno ${ }^{2}$ \\ ${ }^{1,2}$ Universitas Medan Area
}

\begin{abstract}
Not many people use shelter as a place to go up and down, showing how the level of comfort and construction of the shelter that is not in accordance with what is desired by the community, to increase community participation and comfort, the shelter design is done in accordance with the wishes of the community based on the quality function depolymen method (QFD, the research method carried out in this study is to identify consumer perceptions of existing designs and then identify consumers' desires for shelter designs by using the Quality Function Deployment (QFD) the purpose of this research is to design a shelter that suits the customer's needs. The results and conclusion obtained by using QFD

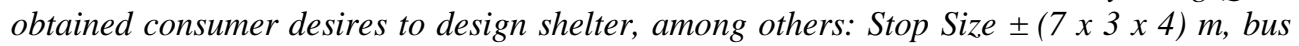
stop lights \pm 3 pieces, Paint colors red and blue stop, Size of the steps are high $\pm 12 \mathrm{~cm}$ and width \pm 30 , Skeletal material made of concrete, Seating material made of stainless, Has the additional function of route information, Has an additional function of price information
\end{abstract}

Keyword: Bus Rapid Transit MEBIDANG, SHELTER, Quality Function Deployment, Accessibility

\begin{abstract}
Abstrak. Belum banyaknya masyarakat yang menggunakan shelter sebagai tempat untuk naik dan turun memperlihatkan bagaimana tingkat kenyamanan dan pembangunan dari shelter yang belum sesuai dengan apa yang diiginkan oleh masyarakat, untuk meningkatkan partisipasi masyarakat dan kenyamanan maka dilakukan perancangan shelter yang sesuai dengan keinginan masyarakat berdasarkan metode quality function depolymen (QFD, Metode penelitian yang dilakukan pada penelitian ini adalah dengan melakukan identifikasi persepsi konsumen terhadap desain yang sudah ada selanjutnya dilakukan identifikasi keinginan konsumen terhadap desain shelter dengan menggunakan metode Quality Function Deployment (QFD). tujuan dalam penelitian ini adalah mendisain shelter yang sesuai dengan kebutuhan pelanggan. Hasil dan kesimpulan yang diperoleh dengan menggunakan QFD diperoleh keinginan konsumen untuk desin halte antara lain. Ukuran Halte $\pm(7 \times 3 x$ 4) $m$, Lampu penerang halte bus \pm 3 buah, Warna Cat halte merah dan biru, Ukuran anak tangga tingginya $\pm 12 \mathrm{~cm}$ dan lebar \pm 30 , Bahan kerangka terbuat dari beton, Bahan tempat duduk terbuat dari stainless, Memiliki fungsi tambahan informasi rute, Memiliki fungsi tambahan informasi hargaa
\end{abstract}

Kata Kunci: Bus Rapid Transit, MEBIDANG. SHELTER, Quality Function Deployment, Aksesbilitas

Received 30 Desember 2019 | Revised 22 Januari 2020 | Accepted 27 Januari 2020

*Corresponding author at: Universitas Medan Area, Medan, 20112, Indonesia

E-mail address: chalisfajri@yahoo.co.id 


\section{Pendahuluan}

Sumatera Utara merupakan propinsi terbesar ke 3 yang memiliki sarana transportasi yang cukup besar berjumlah 2.708.511 kendaraan dengan terus mengalami kenaikan yang cukup signifikan sebesar 23,82\% setiap tahunnya Pertumbuhan angkutan umum yang ada di Medan terus mengalami peningkatan, berdasarkan data dari dinas perhubungan tahun 2015 sebanyak 12.750 jumlah angkutan umum meningkat pada tahun 2016 sebanyak 22.130 anggkutan umum.

Meningkatnya jumlah angkutan umum di kota Medan menimbulkan persoalan transportasi perkotaan. Persoalan tersebut Menurut Tamin (2000), salah satunya adalah kemacetan di daerah perkotaan yang diakibatkan meningkatnya kecenderungan para pemakai jasa transportasi untuk menggunakan kendaraan pribadi dibandingkan dengan kendaraan umum. Menurunnya peranan angkutan umum juga disebabkan oleh rendahnya tingkat pelayanan angkutan umum itu sendiri. Pada dasarnya, tingkat pelayanan yang rendah itu menyangkut sarana dan prasarana yang kurang memadai, waktu tempuh yang cukup lama, jumlah penumpang yang melebihi kapasitas angkut, tingkat kenyamanan yang rendah untuk mengurangi persoalan tersebut maka pemerintah provinsi Sumatera Utara mengeluarkan alat transportasi yang terintegrasi yang diberi nama BRT MEBIDANG (Bus Rapid Transit Medan-Binjai-Deli Serdang).

Perjalanan penumpang di Medan-Binjai-Deliserdang saat ini mencapai lebih dari 600.000 orang per hari. Total tersebut, didominasi oleh pengguna sepeda motor 56,6\%, mobil pribadi $19,3 \%$, dan angkutan umum 20,6\% (Dishub, 2015), untuk mengurangi penggunaan kendaraan pribadi Bus MEBIDANG memiliki fasilitas yang cukup nyaman dan harga yang murah sehingga banyak masyarakat yang ingin menggunakan angkutan tersebut.

Penumpang yang ingin menggunakan alat transportasi tersebut dapat menggunakan shelter yang disediakan oleh pemerintah provinsi Sumatera Utara untuk memudahkan penumpang untuk menunggu BRT MEBIDANG.

Salah satu penunjang yang penting dalam beroperasinya Bus MEBIDANG adalah tersedianya shelter/halte. Jumlah shalter yang ada saat ini lebih kurang 30 unit shelter. Banyaknya shelter yang dibangun oleh pemerintah provinsi belum mengakomodasi kenyamanan yang ada di shelter tersebut

Dari hasil penelitian berdasarkan persepsi dari masyarakat Di Kota Medan halte tidak dilengkapi dengan fasilitas utama maupun tambahan seperti :

1. Identitas halte, berupa nama atau nomor.

2. Informasi tentang rute dan jadwal angkutan umum.

3. Rambu-rambu untuk menjamin keamanan pengguna.

4. Tidak dilengkapi dengan teluk bus untuk melancarkan lalu lintas.

5. Lampu penerangan, Sehingga pada malam hari pengguna halte tidak dapat menggunakan halte untuk menunggu angkutan umum karena kondisinya yang menjadi sangat gelap.

6. Pagar pengaman, agar pejalan kaki tidak menyeberang di sembarangan tempat. 
7. Hanya fasilitas tempat sampah dan telepon umum yang melengkapi beberapa halte di kota Medan.

8. Di Kota Medan halte di bangun diatas trotoar, dan tidak menyisakan ruang untuk pejalan kaki, sehingga pejalan kaki yang melintasi halte tersebut harus menggunakan badan jalan untuk melewatinya. Tentu saja hal ini mengakibatkan pengguna jalan lainnya terganggu.

9. Sedangkan sebanyak $66.7 \%$ halte di Kota Medan merupakan sarana untuk iklan [2]

Desain shelter yang tersedia saat ini jika dilihat dari studi pendahuluan masih jauh dari kenyamanan . Berdasarkan PERMENDISHUB No 27 Tahun 2015 tentang Standar Pelayanan Minimal Angkutan Massal Berbasis Jalan dimana menyatakan "Standar minimal pelayanan pada halte meliputi Lampu Penerangan, Fasilitas Pengatur Suhu atau Ventilasi, Fasilitas Kebersihan, Luas Lantai Perorang, Aksesbilitas",

Perancangan Halte yang mengakomodir aksesbilitas telah dilakukan oleh Hasibuan, 2017 dengan melakukan perancangan shelter terhadap aksesbilitas tetapi tidak melakukan perancangan terhadap fasilitas kenyamanan yang lain oleh karena itu pada penilitian ini akan dilakukan lanjutan perancangan shelter untuk meningkatkan kenyamanan terutama pada standar minimal berdasarkan peraturan permendishub dan juga standar kenyamanan berdasarkan customer need dengan menggunakan Quality Function Deployment

\section{Tinjauan Pustaka}

Sebagian besar penelitian tentang tempat pemberhentian dilakukan dengan mengumpulkan data komponen- komponen yang baik dan buruk, tapi tidak memperhitungkan tingkat kebutuhan dan kepuasan masyarakat dan komponen-komponen tersebut memberikan pengaruh yang sama kepada semua pengguna. Sebagai pengguna, masyarakat merasakan langsung fasilitas yang tersedia di tempat pemberhentian. Hal tersebut menunjukkan bahwa perencanaan tempat pemberhentian bis harus berda sarkan kebutuhan pengguna [2].

Faktor utama dalam penyebab ketidaknyaman, dan ketidakamanan di dalam sebuah halte di Jakarta di timbulkan oleh sikap ketidakdisiplinan dalam diri masyarakat Jakarta sendiri. Selain itu factor lainnya juga di sebabkan oleh lemahnya peraturan pemerintah terhadap masyarakat yang menimbulkan sikap tak disiplin dalam masyarakat Jakarta. [3].

Penelitian Lain Juga menjelaskan hasil identifikasi halte yang terdapat disurabaya Secara garis besar, bila ditinjau dari segi internal dan eksternalnya maka permasalahan yang ada pada halte di Surabaya saat ini adalah:

1. Banyak halte yang berada dalam kondisi rusak, atau tidak memiliki fasilitas yang memadai.

2. Tidak adanya koordinasi yang baik dengan pihak manajemen transportasi umum, sehingga angkutan umum yang ada tidak datang tepat waktu, parkir di sembarang tempat, dan berhenti sembarangan untuk menaikkan penumpang.

3. Sering disalahgunakan sebagai tempat parkir sepeda, tempat berjualan berjualan pedagang kaki lima dan tempat tidur bagi gelandangan. 
4. Desain yang kurang menarik, mengurangi minat masyarakat untuk menunggu di halte dan memilih untuk menunggu di sembarang tempat.

5. Tidak ada sarana bantuan bagi pengguna cacat fisik. [4]

Perancangan ulang terhadap fasilitas umum dibutuhkan pengukuran ergonomi dan fisiologi untuk dapat memenuhi kebutuhan bagi kaum penyandang cacat, seperti penelitian sebelumnya yang dilakukan oleh [5] Perancangan fasilitas untuk orang-orang yang mempunyai kebutuhan khusus (wanita hamil dan orang lanjut usia) harus mempertimbangkan antropometri pengguna, keinginan, dan keterbatasan fisik pengguna, seperti penelitian sebelumnya [6][7][8]

\section{Metodelogi}

Adapun metodelogi yang digunakan dalam penelitian ini antara lain

\section{Penyebaran Kuesioner}

a. Kuesioner terbuka (kuesioner pendahuluan) Kuesioner terbuka ini merupakan tahapan dalam studi pendahuluan yang dilakukan untuk mendapatkan susunan butir-butir pertanyaan yang merupakan isi dari kuesioner sebenarnya (kuesioner tertutup).

b. Kuesioner tertutup Setelah kuesioner terbuka disebarkan, akan didapatkan modus dari jawaban responden. Hasil dari modus jawaban akan disusun dalam kuesioner tertutup yang kemudian dikembangkan dan disesuaikan dengan dimensi kualitas pelayanan menjadi variabel-variabel penelitian serta menggunakan skala interval sebagai skala penilaian.[9]

\section{Uji Validitas Dan Reliabilitas}

Pengujian ini bertujuan untuk mengukur keampuhan dari kuesioner yang telah disusun. Pengujian validitas dilakukan dengan membandingkan harga korelasi perhitungan setiap butir pertanyaan dengan tabel angka kritik korelasi product moment.

$$
r=\frac{n\left(\sum X Y\right)-\left(\sum X \sum Y\right)}{\sqrt{\left[\left(n \sum X^{2}-\left(\sum X\right)^{2}\right)\left[n \sum Y^{2-}\left(\sum X\right)^{2}\right]\right.}}
$$

Sedangkan pengujian reliabilitas kuesioner dilakukan dengan menggunakan harga koefisien Alpha Cronbach.

$$
r=\left[\frac{k}{k-1}\right]\left[1-\frac{\sum \sigma^{2} b}{\sigma^{2} t}\right]
$$

\section{House Of Quality}

Rumah kualitas atau biasa disebut juga House of Quality (HOQ) merupakan tahap pertama dalam penerapan metodologi QFD. Secara garis besar matriks ini adalah upaya untuk mengkonversi voice of costumer secara langsung terhadap Karakteristik teknis atau spesifikasi 
teknis dari sebuah produk (barang atau jasa) yang dihasilkan. House of quality dapat dilihat pada gambar 1.

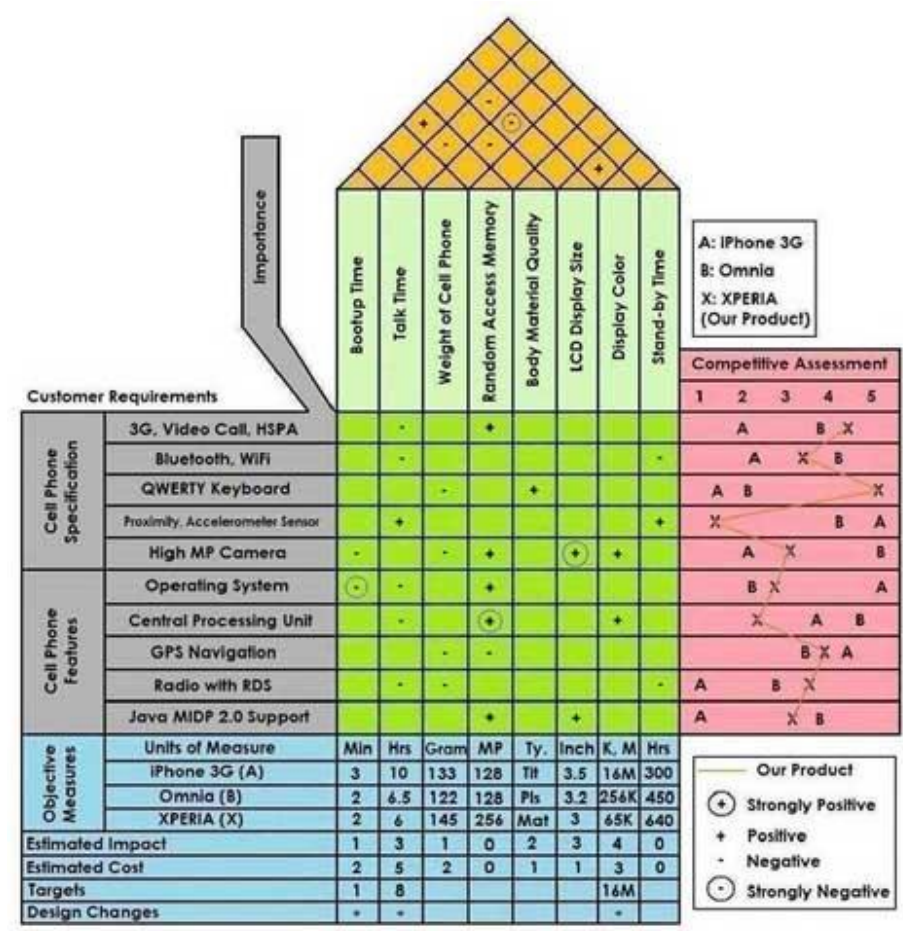

Gambar 1 House Of Quality

\section{Tahap Perancangan Shelter}

Tahap ini meliputi perancangan dimensi shelter bus sesuai dengan data yang diperoleh berdasarkan hasil pengukuran dengan menggunakan metode servqual dan juga dari quality function deployment sehingga kepuasan pelanggan lebih meningkat.

\section{Langka-Langkah Penelitian}

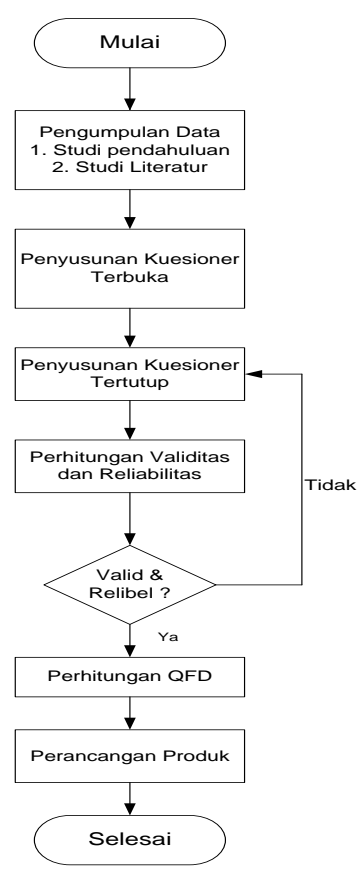


Adapun yang menjadi langkah-langkah penelitian dapat dilihat pada gambar 2 diatas

\section{Hasil dan Pembahasan}

Langkah-langkah quality function deployment (QFD) dengan menggunakan matriks House of Quality adalah sebagai berikut.

\subsection{Mengidentifikasi Keinginan Konsumen Ke dalam Atribut-atribut Produk.}

Untuk mengetahui keinginan konsumen terhadap desain Halte Mebidang maka dalam pengumpulan data dikumpulkan dalam 2 tahap yaitu kuesioner terbuka dan kuesioner tertutup.

Tabel. 1 Data Atribut Halte yang Diinginkan oleh konsumen

\begin{tabular}{ccc}
\hline & Atribut & \\
Primer & Sekunder & Tersier \\
\hline \multirow{3}{*}{ Desain } & Ukuran Halte & $\pm(7 \times 3 \times 4) \mathrm{m}$ \\
& Total Lampu & \pm 3 \\
& Warna Cat & Biru Merah \\
& Ukuran anak tangga & Tinggi $= \pm 12 \mathrm{~cm}$ \\
Bahan & Kerangka & Lebar $= \pm 30$ \\
& Tempat duduk & Beton \\
Multifungsi & Fungsi Tambahan & Informasi rute \\
& & Informasi harga \\
\hline
\end{tabular}

\subsection{Menentukan Tingkat Kepentingan Relatif dari Atribut Produk.}

Penentuan tingkat kepentingan relative atribut ini dilakukan dengan memberikan bobot pada masing-masing atribut dengan menggunakan skala prioritas yang didapart dari kuesioner tertutup dapat dilihat pada tabel

Tabel 2 Data Tingkat Kepentingan dari atribut Produk

\begin{tabular}{cccc}
\hline Primer & Atribut & & $\begin{array}{c}\text { Tingkat } \\
\text { Kepentingan } \\
\text { Produk } \\
\text { Utama }\end{array}$ \\
\hline \multirow{5}{*}{ Desain } & Sekunder & Tersier & 4 \\
& Ukuran Halte & $\pm(7 \times 3 \times 4) \mathrm{m}$ & 4 \\
& Total Lampu & \pm 3 & 3 \\
Bahan & Warna Cat & Biru Merah & 3 \\
& Ukuran anak tangga & Tinggi $= \pm 12 \mathrm{~cm}$ & 3 \\
Multifungsi & Kerangka & Lebar $= \pm 30$ & 3 \\
& Tempat duduk & Bungsi Tambahan & 3 \\
\hline
\end{tabular}




\subsection{Mengevaluasi Atribut Produk Pesaing Yang Sejenis}

Tingkat kepentingan atribut dan pesaing yang diperoleh dari pengumpulan data kuesioner dapat dilihat pada tabel

Tabel. 3 Data Evaluasi Atribut dari produk pesaing yang sejenis

\begin{tabular}{cccc}
\hline \multirow{2}{*}{ Primer } & Atribut & & $\begin{array}{c}\text { Tingkat } \\
\text { Kepentingan } \\
\text { Pesaing 1 }\end{array}$ \\
\hline \multirow{4}{*}{ Desain } & Sekunder & Tersier & 3 \\
& Ukuran Halte & $\pm(7 \times 3 \times 4) \mathrm{m}$ & 3 \\
& Total Lampu & \pm 3 & 3 \\
\multirow{2}{*}{ Bahan } & Warna Cat & Biru Merah & 2 \\
& Ukuran anak tangga & Tinggi $= \pm 12 \mathrm{~cm}$ & Lebar $= \pm 30$ \\
Multifungsi & Kerangka & Beton & 3 \\
& Tempat duduk & Stainless & 2 \\
& Fungsi Tambahan & Informasi rute & 3 \\
& & Informasi harga & 2 \\
\hline
\end{tabular}

\subsection{Menggambarkan matrix perlawanan antara atribut produk dengan karakteristik teknik.}

Atribut yang telah diterjemahkan kedalam karakteristik teknik diletakkan pada bagian vertical di tepi sebelah kiri sedangkan karakteristik teknik dibagian horizontal tepi atas

Tabel 4 Matriks antara Atribut Produk dan Karakteristik Teknik

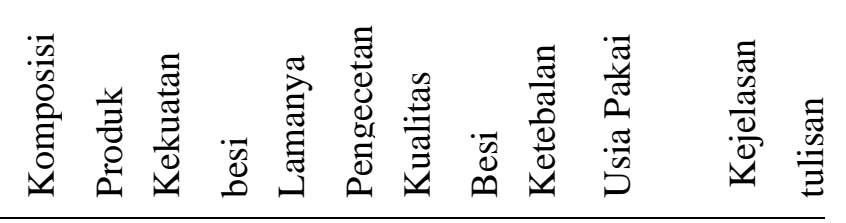

Ukuran halte $\pm(7 \times 3 \times 4) \mathrm{m}$

Total lampu \pm 3 Buah

Warna cat halte merah biru

Ukuran anak tangga Tinggi $= \pm 12 \mathrm{~cm}$ dan Lebar $= \pm 30$

Bahan kerangka terbuat dari beton

Bahan tempat duduk terbuat dari stainless

Fungsi tambahan informasi rute

Fungsi tambahan informasi harga 


\subsection{Mengidentifikasi Hubungan Antara Atribut Produk Dengan Karakkteristik Teknik.}

Dalam hal ini dilakukan dengan menggunakan skor yang tertinggi menunjukkan tingkat kemudahan yang paling tinggi bagi tim perancang untuk mengidentifikasi karakteristik teknik yang paling mempengaruhi kepuasan konsumen.

Tabel 5 Isian Matriks antara Atribut Halte Bus Dan Karakteristik Teknik

Hubungan positif kuat $\quad=4$

Ukuran halte $\pm(7 \times 3 \times 4) \mathrm{m}$

Total lampu \pm 3 Buah

Warna cat halte merah biru

Ukuran anak tangga Tinggi $= \pm 12 \mathrm{~cm}$ dan Lebar $= \pm 30$

Bahan kerangka terbuat dari beton

Bahan tempat duduk terbuat dari stainless

Fungsi tambahan informasi rute

Fungsi tambahan informasi harga

\begin{tabular}{|c|c|c|c|c|c|c|c|c|}
\hline 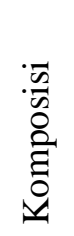 & 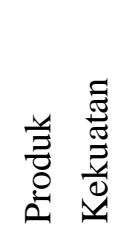 & & 苂 & 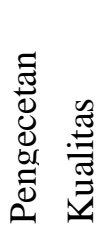 & 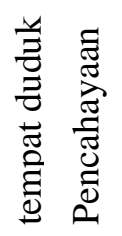 & 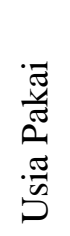 & 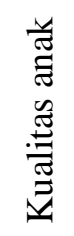 & 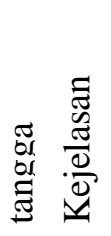 \\
\hline 4 & 4 & 4 & 4 & 1 & 3 & 2 & 1 & 1 \\
\hline 1 & 1 & 1 & 1 & 1 & 4 & 3 & 1 & 1 \\
\hline 1 & 1 & 4 & 4 & 1 & 3 & 4 & 1 & 1 \\
\hline 3 & 3 & 1 & 1 & 1 & 1 & 2 & 4 & 1 \\
\hline 4 & 4 & 1 & 1 & 1 & 1 & 4 & 4 & 1 \\
\hline 4 & 1 & 1 & 1 & 4 & 1 & 4 & 1 & 1 \\
\hline 1 & 1 & 1 & 1 & 1 & 1 & 1 & 1 & 4 \\
\hline 1 & 1 & 1 & 1 & 1 & 1 & 1 & 1 & 4 \\
\hline
\end{tabular}

$\begin{array}{ll}\text { Hubungan positif sedang } & =3 \\ \text { Hubungan negatif sedang } & =2 \\ \text { Hubungan negatif kuat } & =1\end{array}$

4.6. Mengidentifikasi hubungan antara sesame karakteristik teknik

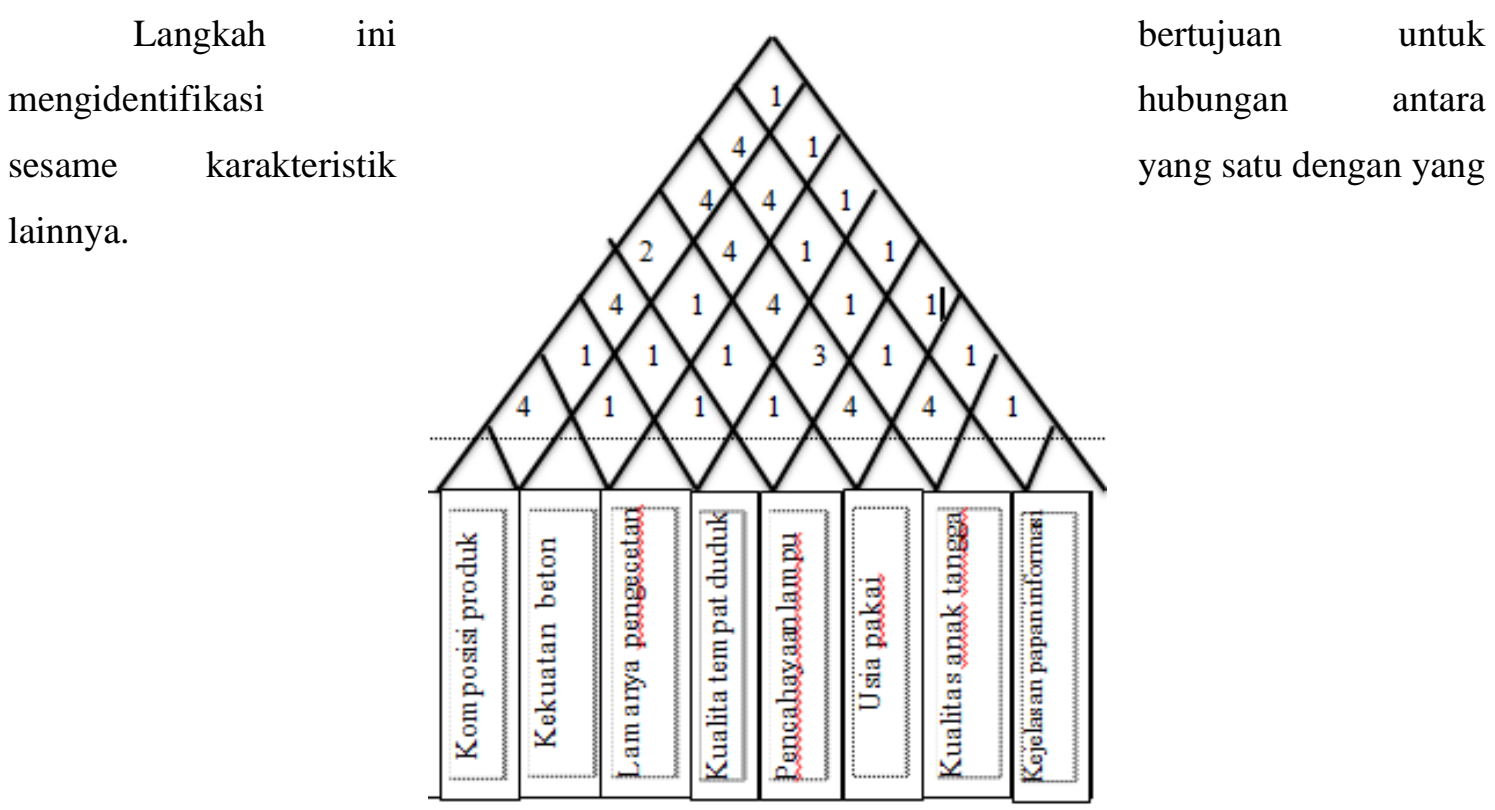

Gambar.3 Hubungan antara sesama Karakteristik Teknik

Hubungan positif kuat $=4$ 
$\begin{array}{ll}\text { Hubungan positif sedang } & =3 \\ \text { Hubungan negatif sedang } & =2 \\ \text { Hubungan negatif kuat } & =1\end{array}$

\subsection{Menetukan target pencapaian untuk setiap karakteristik teknik}

Pada langkah ini ditentukan target yang harus dicapai untuk masing-masing karakteristik teknik, tingkat kesulitan pembuatan, tingkat kepentingan dan perkiraan biaya tingkat masingmasing karakteristik teknik.

Tingkat kesulitan

Total bobot $=58$

1. Komposisi produk

2. Kekuatan beton

3. Lamanya pegecetan

4. Kualitas tempat duduk

5. Pencahayaan lampu

6. Usia Pakai

7. Kualitas anak tangga

8. Kejelasan papan informasi

$$
\begin{aligned}
& =\frac{20}{58} \times 100 \%=34,48 \% \rightarrow 3 \\
& =\frac{16}{58} \times 100 \%=27,58 \% \rightarrow 3 \\
& =\frac{10}{58} \times 100 \%=17,24 \% \rightarrow 1 \\
& =\frac{12}{58} \times 100 \%=20,68 \% \rightarrow 1 \\
& =\frac{11}{58} \times 100 \%=18,96 \% \rightarrow 1 \\
& =\frac{24}{58} \times 100 \%=41,37 \% \rightarrow 5 \\
& =\frac{16}{58} \times 100 \%=27,58 \% \rightarrow 3 \\
& =\frac{8}{58} \times 100 \%=13,79 \% \rightarrow 1
\end{aligned}
$$

Derajat Kepentingan

Total bobot $=124$

1. Komposisi produk

2. Kekuatan beton

3. Lamanya pengecetan

4. Kualitas tempat duduk

5. Pencahayaan lampu

6. Usia Pakai

7. Kualitas anak tangga

8. Kejelasan papan informasi $=\frac{19}{124} \times 100 \%=15,32 \% \approx 15 \%$

$=\frac{16}{124} \times 100 \%=12,90 \% \approx 13 \%$

$=\frac{14}{124} \times 100 \%=11,29 \% \approx 11 \%$

$=\frac{11}{124} \times 100 \%=8,87 \% \approx 9 \%$

$=\frac{15}{124} \times 100 \%=12,09 \% \approx 12 \%$

$=\frac{21}{124} \times 100 \%=16,93 \% \approx 17 \%$

$=\frac{14}{124} \times 100 \%=11,29 \% \approx 11 \%$

$=\frac{14}{124} \times 100 \%=11,29 \% \rightarrow 11 \%$ 
Total bobot $=18$

1. Komposisi produk

2. Kekuatan beton

3. Lamanya pengecetan

4. Kualitas tempat dudu

5. Pencahayaan lampu

6. Usia Pakai

7. Kualitas anak tangga

8. Kejelasan papan informasi

$$
\begin{aligned}
& =\frac{3}{18} \times 100 \%=16,66 \% \approx 17 \% \\
& =\frac{3}{18} \times 100 \%=16,66 \% \approx 17 \% \\
& =\frac{1}{18} \times 100 \%=5,55 \% \approx 6 \% \\
& =\frac{1}{18} \times 100 \%=5,55 \% \approx 6 \% \\
& =\frac{1}{18} \times 100 \%=5,55 \% \approx 6 \% \\
& =\frac{5}{18} \times 100 \%=27,77 \% \approx 28 \% \\
& =\frac{3}{18} \times 100 \%=16,66 \% \approx 17 \% \\
& =\frac{1}{18} \times 100 \%=5,55 \% \approx 6 \%
\end{aligned}
$$

\begin{tabular}{|c|c|c|c|c|c|c|c|c|c|c|}
\hline & 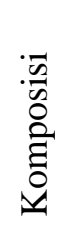 & $\begin{array}{l}\frac{y}{z} \\
0 \\
0 \\
0\end{array}$ & 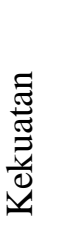 & & 2 & 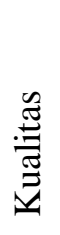 & 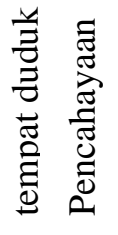 & 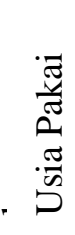 & 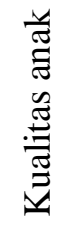 & 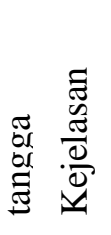 \\
\hline Tingkat Kesulitan & 3 & & 3 & 1 & & 1 & 1 & 5 & 3 & 1 \\
\hline Derajat Kepentingan & 15 & & 13 & & & 9 & 12 & 17 & 11 & 11 \\
\hline Perkiraan Biaya & 17 & & 17 & 6 & & 6 & 6 & 28 & 17 & 6 \\
\hline
\end{tabular}

Tabel 6 Hubungan antara Karakteristik Teknik dengan Tingkat Kesulitan Derajat kepentingan dan perkiraan biaya

Selanjutnya, dapat digunakan House Of Quality (HOQ) yang merupakan gabungan semua karakteristik teknik, atribut yang diinginkan konsumen, posisi produk pesaing dan produk utama terhadap atribut yang sama. Semuanya dibuat dalam rumah mutu dengan menggunakan metode QFD [10]

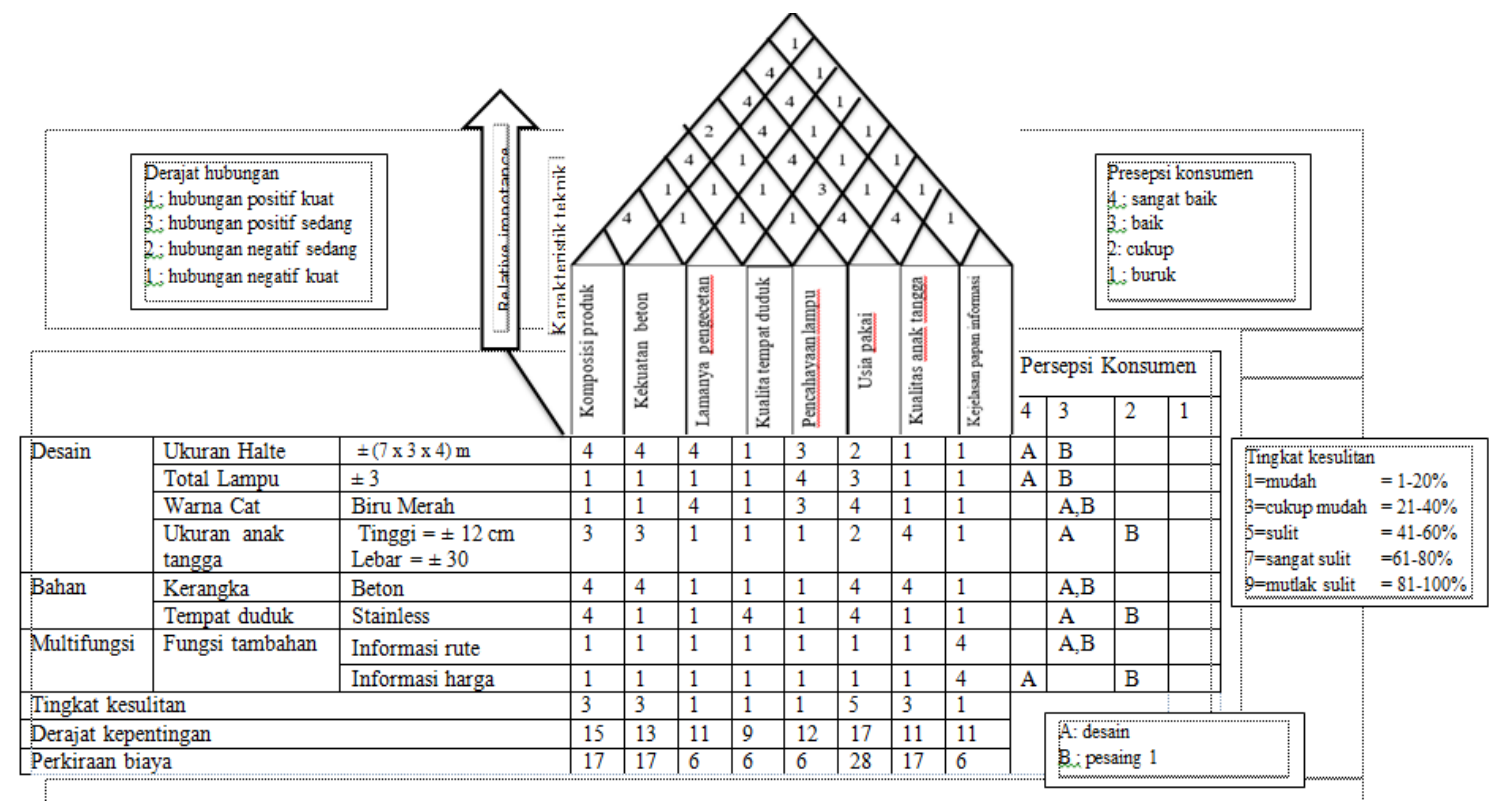




\section{Gamber 4 House Of Quality (HOQ)}

Kesimpulan dari gambar QFD diatas adalah:

1. Atribut Untuk Halte Bus dari hasil quisioner adalah:
a. Ukuran Halte $\pm(7 \times 3 \times 4) \mathrm{m}$
b. Lampu penerang halte bus \pm 3 buah
c. Warna Cat halte merah dan biru
d. Ukuran anak tangga tingginya $\pm 12 \mathrm{~cm}$ dan lebar \pm 30
e. Bahan kerangka terbuat dari beton
f. Bahan tempat duduk terbuat dari stainless
g. Memiliki fungsi tambahan informasi rute
h. Memiliki fungsi tambahan informasi harga

2. Perbandingan halte hasil penyebaran quisioner dengan produk dari pesaing pada atribut yang sama, yaitu:
a. Untuk ukuran halte : Desain lebih unggul dari pesaing.
b. Untuk total lampu : Desain lebih unggul dari pesaing.
c. Warna cat : Desain dan pesaing sama unggul
d. Ukuran anak tangga : Desain lebih unggul dari pesaing.
e. Untuk bahan kerangka halte : Desain dan pesaing sama unggul
f. Untuk bahan tempat duduk : Desain lebih unggul dari pesaing.
g. Untuk fungsi tambahan halte bus menyediakan harga tiket dan informasi rute.

3. Tingkat kesulitan: semua karakteristik teknik tersebut mudan dan cukup mudah untuk dikerjakan, kecuali usia pakai.

4. Tigkat kepentingan: Semua karakteristik teknik tergolong cukup penting hanya usiapakai halte bus yang penting

5. Perkiraan biaya: perkiraan biaya dari produk rancangan tergolong dalam kategori murah hanya komposisi besi, kekuatan besi, usia pakai dan kualitas anak tangga yang tergolong mahal.

\subsection{Desain Akhir}

Dari hasil yang diperoleh dari QFD maka dilakukan desain akhir Halte/Shelter yang sesuai dengan permintaan pelanggan yang dapat dilihat pada gambar dibawah ini 


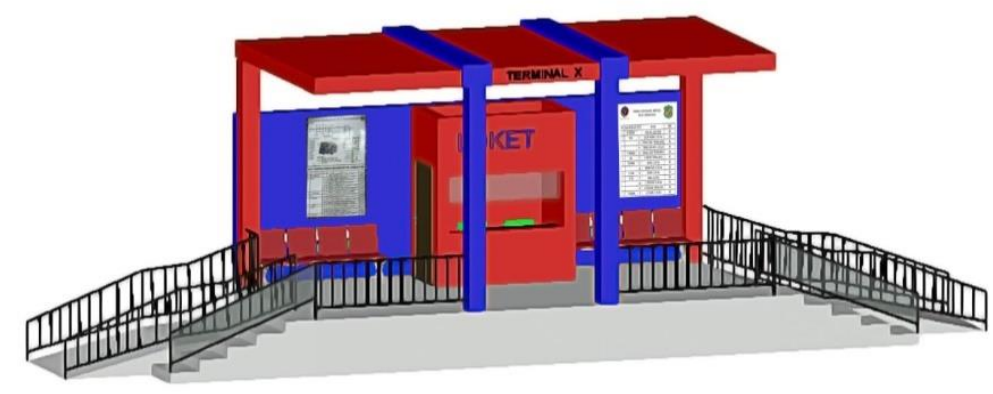

\section{Gambar 5 Desain Akhir Halter Bus/Shelter MEBIDANG}

\section{Kesimpulan}

Hasil yang diperoleh dengan menggunakan QFD diperoleh keinginan konsumen untuk desain halte antara lain

a. Ukuran Halte $\pm(7 \times 3 \times 4) \mathrm{m}$

b. Lampu penerang halte bus \pm 3 buah

c. Warna Cat halte merah dan biru

d. Ukuran anak tangga tingginya $\pm 12 \mathrm{~cm}$ dan lebar \pm 30

e. Bahan kerangka terbuat dari beton

f. Bahan tempat duduk terbuat dari stainless

g. Memiliki fungsi tambahan informasi rute

h. Memiliki fungsi tambahan informasi harga

\section{Daftar Pustaka}

[1] Tamin, O.Z., 2000, Pemodelan Sisem Transportasi, Institut Teknologi Bandung, Bandung

[2] Lesmana, W. 2015. Perancangan Interior Fasilitas Tunggu Transportasi Umum di Surabaya Jurnal Intra vol. 3, no. 2, (2015) 196-207

[3] Kurniawan, 2011. Desain Halte Untuk Masyarakat Urban (Studi Kasus : Daerah Jakarta Dan Sekitarnya), Inosains Volume 6 Nomor 1, Februari 2011

[4] Hasibuan, Chalis, 2017, Rancangan Shelter/Halte Brt Mebidang (Bus Rapid Transit MedanBinjai-Deliserdang) Untuk Mempermudah Aksesbilitas Masyarakat Kebutuhan Khusus Dengan Pendekatan Ergonomi, LP2M Universitas Medan Area

[5] Nevala-Puranen, Nina; Markku Seuri; Ahti Simola; and Jyrki Elo. 1999. Physically Disabled at Work: Need for Ergonomic Interventions. Journal of Occupational Rehabilitation. Vol. 9, No. 4

[6] Suhardi, Bambang; dan Sudadi. 2013. Perancangan Tempat Tidur Periksa Untuk Orang Lanjut Usia. Prosiding Seminar Nasional Terpadu Keilmuan Teknik Industri. Malang: Program Studi Teknik Industri Universitas Brawijaya. 
[7] Suhardi, Bambang; dan Fitri Yulianti Suryono. 2013. Perancangan Kursi Bus Untuk Wanita Hamil Berdasarkan Aspek Ergonomi. Prosiding Seminar Nasional Terpadu Keilmuan Teknik Industri. Malang: Program Studi Teknik Industri Universitas Brawijaya

[8] Navas V. G., Helena. 2013. T R I Z : Design Problem Solving with Systematic Innovation, Advances in Industrial Design Engineering, ISBN: 978-953-51-1016-3, InTech, DOI: $10.5772 / 55979$.

[9] Devy, D.S. 2012 Perancangan Tas Ransel Laptop Multifungsi Menggunakan Metode Rasional, Dokumen Tugas Akhir, Program Studi Teknik Industri - S1 | Fakultas Teknik | Universitas Dian Nuswantoro Semarang

[10] Eko Wahyu Runantoro.2005. Usulan Perbaikan Desain Produk Tas Ransel Consina Untuk Penggiat Kegiatan Alam Bebas Dengan Menggunakan Metoda Quality Function Deployment (Qfd). Jurusan Teknik Industri, Fakultas Teknik. Unikom. Bandung 